\title{
Virtual reality for the treatment of posttraumatic disorders
}

This article was published in the following Dove Press journal:

Neuropsychiatric Disease and Treatment

7 April 2016

Number of times this article has been viewed

Thiago Mazzoli Moraes'

Almir Ferreira de Andrade ${ }^{2}$ Wellingson Silva Paiva ${ }^{2,3}$

'Division of Psychology, ${ }^{2}$ Division of Neurosurgery, University of São Paulo Medical School, São Paulo, SP, Brazil; ${ }^{3}$ Neurology Center, Samaritano Hospital, São Paulo, SP, Brazil
Correspondence: Wellingson Silva Paiva Division of Neurosurgery, University of São Paulo Medical School, Alves Guimarães Street 470, 05410000 São

Paolo, SP, Brazil

Tel +55 II 25486900

Fax +55 || 25486906

Email wellingsonpaiva@yahoo.com.br

\section{Dear editor}

We read with great interest the recent study by Botella et al ${ }^{1}$ published in the journal Neuropsychiatric Disease and Treatment. Virtual reality (VR) technology has allowed for the neuropsychological rehabilitation in patients with many neurological diseases including stroke and traumatic brain injury. ${ }^{2,3}$ This contribution is due to the VR's ability to create standardized environments (replicable and ecological) that are difficult to deliver and control in the real world. ${ }^{4,5}$ For example, exercises that would be too dangerous to be performed and practiced in the real world could be done in a virtual environment. The implementation of VR systems could allow the involvement of specialists and caregivers to easily modify the tasks according to the needs and difficulties of the patient. ${ }^{6}$ Botella et al's ${ }^{1}$ paper focused on reviewing the use of virtual reality exposure-based therapy (VR-EBT) and its adequacy, acceptability, and efficacy in the treatment of patients with posttraumatic stress disorder.

Botella et al ${ }^{1}$ performed a broad review about the use of VR-EBT, discussing the recommended duration, periodicity, and number of sessions. This way, the authors showed a relative lack of standardization among the articles reviewed, making the comparison of results difficult. However, the recommended session duration proposed by the authors ( 90 minutes) should be interpreted with caution. Exposure to VR can lead to symptoms of cybersickness, for example, eye strain, headache, sweating, nausea, and disorientation. ${ }^{6}$ These symptoms can be enhanced by the type of technology used and the amount of time the person was exposed to it. In this review by Botella et al, ${ }^{1}$ most articles used a head-mounted display (nine out of 12 ) as the VR device. Head-mounted displays have been reported to cause increased levels of nausea compared with desktop viewing. ${ }^{7}$ This effect can be diminished with the use of a head-tracking system, higher quality devices, and devices with lower latency. ${ }^{6}$

Despite the exhaustive discussion of treatments in this paper, some considerations were not included; the type of VR device and the quality of the virtual environment may have influenced the results obtained and if the gain achieved by the treatment with virtual reality justify the increased cost. Finally, they failed to consider an aspect that we believe is important in clinical use of VR system: the importance of the therapist involvement in the treatment outcome. So, as described by Botella et al, ${ }^{1}$ VR-EBT in the treatment of neuropsychiatric diseases is a promising method. These small caveats, however, do not take away the main relevant messages and discussion raised by Botella et al. ${ }^{1}$ 


\section{Disclosure}

The authors report no conflicts of interest in this communication.

\section{References}

1. Botella C, Serrano B, Baños RM, Garcia-Palacios A. Virtual reality exposure-based therapy for the treatment of post-traumatic stress disorder: a review of its efficacy, the adequacy of the treatment protocol, and its acceptability. Neuropsychiatr Dis Treat. 2015;11:2533-2545.

2. García-Betances RI, Jiménez-Mixco V, Arredondo MT, CabreraUmpiérrez MF. Using virtual reality for cognitive training of the elderly. Am J Alzheimer Dis Other Demen. 2015;30(1):49-54.

3. Gamito P, Oliveira J, Coelho C, et al. Cognitive training on stroke patients via virtual reality-based serious games. Disabil Rehabil. Epub 2015 July 2.
4. Gervasi O, Magni R, Zampolini M. Nu! RehaVR: virtual reality in neuro tele-rehabilitation of patients with traumatic brain injury and stroke. Virtual Reality. 2010;14(2):131-141.

5. Joseph PA, Mazaux JM, Sorita E. Virtual reality for cognitive rehabilitation: from new use of computers to better knowledge of brain black box? Int J Disabil Hum Develop. 2014;13(3):319-325.

6. LaViola JJ Jr. A discussion of cybersickness in virtual environments. ACM SIGCHI Bull. 2000;32(1):47-56.

7. Sharples S, Cobb S, Moody A, Wilson JR. Virtual reality induced symptoms and effects (VRISE): comparison of head mounted display (HMD), desktop and projection display systems. Displays. 2008;29(2): $58-69$.

Dove Medical Press encourages responsible, free and frank academic debate. The content of the Neuropsychiatric Disease and Treatment 'letters to the editor' section does not necessarily represent the views of Dove Medical Press, its officers, agents, employees, related entities or the Neuropsychiatric Disease and Treatment editors. While all reasonable steps have been taken to confirm the content of each letter, Dove Medical Press accepts no liability in respect of the content of any letter, nor is it responsible for the content and accuracy of any letter to the editor.

\section{Publish your work in this journal}

Neuropsychiatric Disease and Treatment is an international, peerreviewed journal of clinical therapeutics and pharmacology focusing on concise rapid reporting of clinical or pre-clinical studies on a range of neuropsychiatric and neurological disorders. This journal is indexed on PubMed Central, the 'PsycINFO' database and CAS, and is the official journal of The International Neuropsychiatric Association (INA). The manuscript management system is completely online and includes a very quick and fair peer-review system, which is all easy to use. Visit http://www.dovepress.com/testimonials.php to read real quotes from published authors.

Submit your manuscript here: http://www.dovepress.com/neuropsychiatric-disease-and-treatment-journal 